\title{
BURNOUT SYNDROME AMONG ROMANIAN TEACHERS DURING PANDEMIC
}

\author{
SIMINA-NICOLETA BOHÂLȚEANU ${ }^{i}$
}

\begin{abstract}
The emergence of the global pandemic context has led to rapid and important changes in education systems, from school closures and the transition to online classroom learning, to forcing teachers and students to adapt quickly to this new type of learning. The pandemic context thus determined the emergence of new challenges in the activity of teachers with an impact on their state of exhaustion. The purpose of this research is to identify the level of exhaustion experienced at work by teachers in Romania during the pandemic. Data were collected from 47 Romanian teachers through a google form. The data were analyzed using the SPSS Statistics program, using descriptive analyzes and group comparison tests. The results of the study show that responding teachers experience a moderate level of emotional exhaustion, a low level of depersonalization and a high level of personal achievement.
\end{abstract}

Keywords: Burnout syndrom, exhaustion, teachers, pandemic context

\section{INTRODUCTION}

Burnout syndrome is one of the major challenges of today's modern society, given the dynamics of jobs and implicitly their increasingly diverse requirements, as well as the ever-evolving technology. The pressure felt by employees in various fields of activity and industries causes them to suffer from work stress, fatigue and even exhaustion.

Exhaustion at work is considered a professional hazard, especially for those professions that are people-oriented (for example in education, health care, etc.). In this regard, the teaching profession has been identified as one of the most stressful

\footnotetext{
i Alexandru Ioan Cuza University of Iaşi, Doctoral School of Economics and Business Administration, Iaşi, Romania,e-mail: bohalteanu_simina@yahoo.ro
} 
occupations, with specific activities affecting physical and psychological wellbeing, as well as job satisfaction (Johnson, et al., 2005).

Burnout syndrome is understood by specialists as a result of long-term occupational stress, whose symptoms and effects are experienced differently by employees and although the reasons for its occurrence may be different, all are exposed to a certain level of stress at work, including teachers (Jennett, et al., 2003).

Exhaustion at work can be considered a professional risk, in view of the existing consequences, but also a phenomenon that is induced by suffering (Beheshtifar and Omidvar, 2013), characterized by three specific dimensions: emotional exhaustion, depersonalization and reduced feeling of realization (Maslach and Leiter, 2016).

The teaching profession involves many satisfactions and challenges, but mismanaged by teachers or managers can contribute to their exposure to prolonged stress, which will lead to decreased job satisfaction, and the occurrence of chronic burnout in the form of burnout syndrome. The implications of this syndrome are found both at the level of individuals (teachers may feel disturbed physically, mentally and professionally) and at the level of school (absenteeism, inefficient teachers, overworked work environment that affects the well-being of colleagues, unprepared students - poor quality of the educational act).

The emergence of the pandemic context has led to restructuring in terms of how to carry out work activities in almost all areas of activity. Thus, working from home during the pandemic made the line between professional and personal life difficult to delimit, given the numerous activities to be performed at the same time (work tasks combined with household tasks, changes in social interactions, etc.).

The emergence of the global pandemic context has led to rapid and important changes in education systems, from school closures and the transition to online classroom learning, to forcing teachers and students to adapt quickly to this new type of learning. Or, this essential change in the life of teachers has made homework a significant challenge for some of them, especially in terms of management, as with a lack of control over how to perform new tasks, stress and exhaustion intensified.

Although the signs of exhaustion among teachers may go unnoticed by managers and even unrecognized by teachers, it is essential to identify early the symptoms they experience, so as to implement the most effective and effective intervention plans to maintain or even the increase of their well-being, implicitly of the qualitative level of education. 
The need to know the level of exhaustion at work is all the more important as its effects can be felt in the long term in other aspects of the individual's life, and ignoring the symptoms of exhaustion by managers and employees can lead to worsening physical and mental health. as well as affecting organizational performance.

\section{LITERATURE REVIEW}

\section{a. Burnout syndrome - concept}

In the foreign literature there is an increased interest in studying this burnout syndrome due to its importance in the social life (increasing interest in mental health) of individuals, which has contributed to various opinions about its significance.

The results of the research conducted by Heinemann and Heinemann (2017) on the typology of research on the phenomenon of burnout show that there are six such categories: studies that considered the causes and factors associated with burnout (identified as personality factors, factors organizational, social factors); studies aimed at the prevalence of this syndrome in certain occupational groups; studies aimed at developing and testing methods to prevent or reduce burnout; studies that focused on identifying the psychological symptoms of burnout; psychometric studies; studies that looked at the physiological processes underlying burnout syndrome.

According to APA Dictionary of Psychology (2020) the meaning of the concept of burnout is that of "physical, emotional or mental exhaustion accompanied by low motivation, poor performance and negative attitudes towards self and others", being present among professionals such as: social workers, teachers, therapists, athletes, etc. Herbert Freudenberger first defined this concept in 1975 to describe a certain experience and mental state at work.

Schaufeli, Marek and Maslach (1993) argue that burnout can be described in terms of three elements:

- Emotional exhaustion understood by the individual as a lack of energy and consumption of emotional resources.

- Depersonalization that implies the existence of a feeling of distance of the employee from the work done.

- Low personal achievement - seen from a negative perspective (negative evaluation trend).

According to the definition given by the World Health Organization (2019), burnout is a syndrome caused by the individual's exposure to chronic stress at work, characterized by three dimensions: the existence of a feeling of exhaustion, a 
feeling of detachment from the place work (or a negative feeling towards the workplace), a feeling of inefficiency and lack of achievement. According to the code assigned in the International Classification of Diseases and Related Problems (ICD-11), exhaustion is seen as a phenomenon in the occupational context, which refers to mental well-being at work.

Exhaustion at work is defined as a psychological syndrome caused by the action of chronic interpersonal stressors at work (Maslach and Leiter, 2016), more specifically it is a consequence of a perceived disparity between the employee's requirements and resources (material and emotional) that he has at his disposal (Beheshtifar and Omidvar, 2013).

The significance of the concept of burnout at work differs from the significance of similar terms, such as stress at work and depression in that burnout implies an attitude of cynicism and a feeling of inefficiency towards workplace stress (Cordes and Dougherty, 1993; Schaufeli and van Dierendonck, 1993), and that depression (which occurs in a free context, covering all areas of life) is related to the occupational context (Warr, 2007).

Psychology Today defines exhaustion as a state of emotional, mental and sometimes even physical exhaustion, caused by prolonged exposure to stress, and most often caused by problems at work.

\section{b. Teacher exhaustion - causes, symptoms and effects}

Education is a pillar of a strong modern society, being represented by teachers - the main promoters and guarantors of quality in education. The teaching profession in the 21 st century involves a number of significant challenges for those working in the field of education, which can bring both satisfaction and exhaustion. Among the specific challenges of the educational career we can mention: adapting the contents of the curricula to the diversity of students 'learning styles, managing the students' class (with everything that means leadership, motivation, problem solving, mentoring, evaluation, etc.), identifying the most appropriate ways to assimilate changes in education, so that students do not suffer, solving administrative tasks, concern for continuous professional development, etc.

\section{Causes}

Research in the field shows that many teachers experience burnout at work in terms of how to approach the daily challenges specific to work, and are then exposed to prolonged emotional stress. Thus, Ajayi (2016), McAllister (2018) consider that the evaluation of students by complying with certain standardized 
tests leads to stressful situations among them, but also among teachers. In addition, Ávalos (2011) points out that there are many concerns and concerns among novice teachers, and that educational requirements in relation to professional development programs create pressures. Fernet, Guay, Senecal and Austin (2012) show in their study that teachers 'perceptions of classroom overload and disruptive behavior of students are in a negative relationship with motivation, which ultimately influences teachers' level of exhaustion. In other words, teachers who are not motivated will consider that they do not have enough time to complete homework, which will make them feel inefficient and exhausted.

The results of Skaalvik and Skaalvik's (2010) study show that teachers' emotional exhaustion is strongly correlated with time pressure (given the feeling of having difficult work tasks, long time- evening, weekend- preparation for teaching, little time for rest and recovery), and the feeling of depersonalization is closely related to the relationship between teachers and parents.

The School of Education (2021) highlights some of the causes that lead to teacher burnout in the workplace:

- poor funding for the purchase of materials, technology to support the teaching-learning act carried out by the teacher (in this sense, teachers feel demotivated).

- high emotional demands: teachers feel the pressure of having on their shoulders the responsibility for future generations, teachers are the ones who also have the role of counselor (come into contact with tragic situations in the lives of students).

- inadequate teacher training in certain disciplinary areas (unsatisfied learning needs of students lead to feelings of dissatisfaction among teachers).

- challenging teaching situations: with e-learning, teachers have had to deal with various situations such as the challenging behavior of students and parents and thus feel more pressure to find a balance between personal and professional life.

Other factors that may contribute to teachers experiencing exhaustion at work may be: failure to manage a class of students (Reeves, 2012); low level of empowerment (Dierking and Fox, 2013); negative work environment (Norhisham, et al., 2021), lack of organizational support (Smetackova, et al., 2019).

The results of the study by Pyhältö, et al. (2021) indicate that there are a number of individual factors that influence the occurrence of teacher exhaustion in the workplace, such as: level of education, gender (female teachers are more likely to experience stress in unjustifiably, and male teachers are more likely to experience feelings of cynicism), years of experience. 
The pandemic context determined the appearance of more accentuated causes in the activity of teachers with impact on their state of exhaustion, such as: more time needed to complete tasks, the need for training in order to easily adapt to new teaching-learning methods, lack of interaction direct with students and coworkers, the need to find the most appropriate methods of motivating and supporting students in such a context (Mogonea \& Mogonea, 2021).

\section{Symptoms}

Drummond (2016) considers that burnout syndrome has its origin in the energy metabolism of individuals, which once disturbed can lead to the following symptoms, considered to be internal energy accounts: decreased levels of emotional and physical energy, decreased levels of compassion and so on. accentuating the feeling of cynicism, accentuating the states of concern about how well the work is done - lack of efficiency.

Burnout syndrome can be manifested by various symptoms (physical, emotional, behavioral) specific to the 12 stages identified by psychologist Herbert Freudenberger and listed by Kaschka, Korczak, and Broich (2011) in their study. Thus, these phases are:

1) excessive ambition - especially for people who are facing something new and who want to prove that they are capable - a new job, a new task

2) more work done

3) neglect of one's own needs (needs for sleep, food, etc.)

4) displacement of the conflict (it is not the employee's fault)

5) less time to complete tasks (even less time spent with loved ones)

6) denying the existence of a problem (not taking responsibility for one's own actions and behaviors)

7) withdrawal (individuals perceive a lack of direction)

8) behavioral changes (individuals become more aggressive)

9) depersonalization (self-removal, individuals feel detached from their own lives and needs)

10) anxiety (individuals look for certain activities to help them cope with these emotions - most often they are negative and addictive)

11) depression (individuals lose their meaning in life)

12) physical exhaustion that may endanger the lives of individuals.

Lowenstein (1991) points out some of the signs that may show that teachers suffer from burnout at work, such as: exhaustion, detachment, boredom, cynicism, impatience, irritability, feelings of being incompetent and unappreciated, paranoia and disorientation, complaints and depression. 
The graide net work (2019) summarizes some of the symptoms identified in several specialized studies, such as: feelings of failure and overwhelm in terms of many specific activities (grading, assessment, preparation), feelings of frustration (teachers consider that they do not have the ability to change the system), stress from managing classroom problems, lack of support, physical problems associated with stress and overwork.

\section{Effects}

Regarding the consequences of this syndrome among employees, Salvagioni, and others (2017) conducted a qualitative analysis of a number of 36 articles on this topic, resulting in the following:

- the state of exhaustion at work affects the physical health of individuals; they are more prone to the following diseases: cholesterol, type 2 diabetes, cardiovascular disease, musculoskeletal disorders, gastrointestinal and respiratory problems, etc.

- the state of exhaustion at work affects the mental health of individuals: they are more prone to insomnia, depressive symptoms, mental disorders.

- the state of exhaustion at work has professional consequences: employees are more prone to experience dissatisfaction at work, absenteeism, the emergence of new pensions for mental illness, presence at work while not feeling well.

Jacobson (2016) concludes in his paper that teacher exhaustion can lead to wear and tear if the influencing factors are not managed effectively, but also to negative results among students due to the low level of teacher commitment (felt in situations of experiencing exhaustion). In addition, it highlights other effects of teacher exhaustion, in terms of studying the literature, such as: exhausted teachers are more prone to experience acts of violence and lose patience, to be absent and thus affect the quality of education, but also well-being colleagues. A similar opinion is shared by Shen and others (2015), who believe that the state of exhaustion at work among teachers affects students' motivation to learn. On the other hand, Leung \& Lee (2006) show that teachers' emotional exhaustion underlies their intentions to leave the profession.

\section{c. Exhaustion of teachers in the pandemic}

The pandemic context has challenged the teaching profession to new challenges, with the transition of learning in the digital environment. At the same time, they were more pronounced with the return to class and the need to address 
new ways of training (such as hybrid learning). Thus, in a new context (of digitalization of learning) teachers have faced new job requirements (complementary or additional to existing ones), with new expectations from education actors (educational bodies, principals, students, parents).

Bohâlțeanu (2021) identifies a series of features of the teacher that have been accentuated in a pandemic context, which has determined that the work done by him becomes much more challenging (and in this sense, maybe even more exhausting). These include: creativity (derived from the need to keep students' attention and actively involved), the need for continuous training (derived from the use of digital educational platforms), the roles of motivator, guide and mentor (derived from the need to be closer of students in a different form, in order to support positive thinking among students); patience and communication.

The results of research aimed at studying the level of burnout among teachers in a pandemic context show that they experienced high levels of burnout at work, women being more affected than men, and those with more experience felt lower levels of exhaustion (Sánchez-Pujalte, et al., 2021), which led to the early leaving of the profession (Diliberti, 2021).

Sokal, Trudel and Babb (2020) studied the relationships between requirements, resources specific to the teaching profession and the state of exhaustion felt by teachers in a pandemic context. Thus, the results of their study indicate that time management, technical issues, the relationship with parents, the balance between personal and professional life are closely related to teacher exhaustion, while lack of resources is in a negative correlation. with the size of the realization.

Pressley (2021) notes that during the pandemic, teachers experienced a high level of exhaustion, with a positive correlation between this condition and anxiety about COVID-19, anxiety about teaching requirements and administrative support.

The results of the study by Weißenfels, Klopp and Perels (2021) indicate that the challenge posed by the pandemic context in teachers' work was not work overload, but rather lack of resources, which intensified feelings of depersonalization and lack of achievement among them.

\section{RESEARCH METHODOLOGY}

\section{a. Purpose and objectives}

The purpose of this research is to identify the level of exhaustion experienced at work during the pandemic by teachers in Romania. 
In order to achieve the goal, the following objectives were set:

1. identifying the level of emotional exhaustion among teachers

2. identifying the level of depersonalization among teachers

3 . identifying the level of achievement among teachers

4. identifying differences at group level in terms of level of exhaustion.

\section{b. Research hypotheses}

In order to achieve these objectives, the following hypotheses of the study were drawn:

H1. In a pandemic context, teachers feel high levels of emotional exhaustion.

H2. In a pandemic context, teachers feel high levels of depersonalization.

H3. In a pandemic context, teachers feel low levels of achievement.

\section{c. Research design}

In order to identify the average general level of exhaustion felt by teachers during the pandemic, we opted for a quantitative approach, more specifically to the research method called investigation. The working tool used was the online questionnaire, in the form of a google form, in order to collect as much information as possible from the respondents. Statistical data processing was performed using the SPPS Statistics program, version 22, running descriptive analyzes, independent samples t-test.

\section{d. Target population and working tool}

The target population was represented by the entire teaching staff of Romanian education, and the sampling was random.

The questionnaire was structured in two parts, aiming at gathering information on the exhaustion syndrome and the socio-demographic characteristics of the respondents.

In order to identify the level of exhaustion among teachers, it was decided to translate into Romanian the Maslach Burnout Inventory-Educator Survey (MBI-ES) scale (taken from Gaitan, 2009), composed of 22 items structured on the three specific dimensions: emotional exhaustion (items 1, 2, 3, 6, 8, 13, 14, 16, 20), depersonalization (items 5, 10, 11, 15, 22) and achievement (items 4, 7, $9,12,17,18,19,21)$. The measurement scale is composed of 7 response variants that indicate the frequency of occurrence of the respective state, as follows: $0=$ never; $1=$ at least several times a year; $2=$ at least once a month; $3=$ several times a month; $4=$ once a week; $5=$ several times a week; $6=$ every day. In 
order to interpret the results obtained, the figures are cumulated by item categories, and the scores obtained indicate:

- For emotional exhaustion: between 0-16 low level, between 17-26 moderate level, over 27 high level.

- For depersonalization: between 0-6 low level, between 7-12 moderate level, over 13 high level.

- For personal achievement the scale is reversed: over 37 low level, between 31-36 moderate level, 0-30 high level.

Examples of questions specific to the three dimensions of exhaustion syndrome are: (1) I feel emotionally exhausted because of the work I do; (2) I feel exhausted at the end of the working day.; (7) I deal effectively with the problems of my students; (12) I feel full of energy .; (13) I feel frustrated by the work I do.; (15) I'm not very interested in what happens to many of my colleagues.; (18) I feel motivated when I work closely with my students.; (22) I feel that the students blame me for some of their problems.

The socio-demographic characteristics targeted among the respondents are: gender, position held (substitute teacher, tenured teacher, master teacher, principal, other position), level of education (primary, secondary, high school, vocational, post-secondary, higher), type of education (public, private), age (18-24, 25-40, 41$56, \geq 57$ years), disciplinary area, educational degree, experience in education (110 years, $11-20$ years, $\geq 21$ years), county.

\section{RESULTS AND DISCUSSIONS}

Following the application of the online questionnaire, information was collected from 47 respondents whose socio-demographic characteristics are the following:

- Gender: 15 males and 32 females

- Position held: all respondents hold teaching positions, most of them full-time teachers (33 of the respondents)

- Level and type of education: most respondents (31) work in state high school education (46 respondents)

- Age: 29 respondents are teachers of generation X (41-56 years), and 12 respondents are teachers of generation $\mathrm{Y}$ (25-40 years), and the rest are aged between 18-24 years (1) and $\geq 57$ years (5)

- Disciplinary area: most of the respondents are part of the department of technologies (15), followed by those of the departments of mathematics and sciences (10) and language and communication (9) 
- Educational degree: 24 respondents have a 1st degree, and 11 have a final degree.

- Experience in education: 14 respondents are between 1-10 years old, 15 respondents are between 11-20 years old, and 18 respondents are $\geq 21$ years old).

- County: 31 respondents are from Iași county, and the rest from other counties, such as: Dolj, Neamţ, Bistrița-Năsăud, etc.

As the original scale was translated into Romanian in order to collect information from Romanian respondents, in order to test the reliability of the working tool, an internal consistency analysis was run, by calculating the Cronbach alfa coefficient. According to table no. 1, the value of this coefficient of 0.890 indicates that there is a strong consistency of the items in terms of the measured construct.

Table 1 Test reliability

\begin{tabular}{|c|c|c|}
\hline Cronbach's Alpha & $\begin{array}{c}\text { Cronbach's Alpha Based on } \\
\text { Standardized Items }\end{array}$ & N of Items \\
\hline .890 & .891 & 22 \\
\hline
\end{tabular}

Regarding the identification of the levels of exhaustion (on the three specific dimensions) and anxiety towards COVID-19 of the respondents, it was decided to compute the items by dimensions, and then to calculate the averages per group. In this sense, the results from table no. 1 indicates the following:

- Responding teachers experience a moderate level of emotional exhaustion (with a score of 19 rated on a scale of 17-26)

- Responding teachers experience a low level of depersonalization (with a score of about 6 rated on a scale of 0-6)

- Responding teachers feel a high level of personal achievement (with a score of 30 rated on a scale of $0-30$ ).

Table 2 Descriptive analysis of the specific dimensions of burnout syndrome

\begin{tabular}{|c|c|c|c|c|c|}
\hline & $\mathbf{N}$ & Minimum & Maximum & Mean & Std. Deviation \\
\hline Emotional exhaustion & 47 & .00 & 48.00 & 19.1915 & 12.12371 \\
Depersonalization & 47 & .00 & 28.00 & 5.7872 & 5.90481 \\
Personal achievement & 47 & 7.00 & 48.00 & 30.6383 & 11.64778 \\
Valid N (listwise) & 47 & & & & \\
\hline
\end{tabular}

In order to identify differences at the level of groups in terms of the level of emotional exhaustion, it was decided to run a test to compare the averages by groups of respondents by gender, age, educational level, years of experience. The 
results of the independent samples t test indicated that there were no differences in the perceived level of emotional exhaustion among the respondents in the analyzed groups, the sig values being higher than 0.05 .

These results may indicate that teachers have now adapted to the new challenges posed by the pandemic context and have managed not to disconnect from what the teaching profession means and thus diminish the feeling of cynicism. Another explanation for these results may be that teachers now feel that they are effective because they have so far managed to learn and learn to work in class with digital tools so as to better manage specific activities compared to the beginning period. However, the results indicate that teachers still feel a moderate level of emotional exhaustion, which, however, cannot necessarily be attributed to the pandemic context, but to the nature of the work itself (the teaching profession). Thus, according to the identified results we can say that the working hypotheses $\mathrm{H} 1, \mathrm{H} 2$, H3 are rejected.

\section{Conclusions}

The results of this study objectively reflect the overall picture of burnout syndrome among teachers, by highlighting its main causes, symptoms and effects on their personal and professional lives. In addition, it highlights the main manifestations of burnout at work among teachers in a pandemic context.

Due to the increasing frequency of this symptom in several professions, but especially in the teaching profession and starting from the analysis of the literature, this study sought to identify the level of burnout at work felt by teachers in Romania.

In this regard, an online questionnaire on this construct was applied, and the results obtained show that teachers generally do not experience burnout at work in this pandemic context. Of the three dimensions specific to this syndrome, emotional exhaustion is more felt by teachers than the other two (depersonalization and personal achievement), but all at a moderate level. The results of this study are not similar to those of other studies (Pyhältö, et al., 2021; Sánchez-Pujalte, Mateu, Etchezahar and Gómez, 2021), which show that in a pandemic context teachers experience high levels of exhaustion and felt differ depending on certain sociodemographic characteristics.

Knowing these levels of emotional exhaustion, cynicism, achievement, experienced by teachers contributes to the objective assessment of reality and thus to making the most appropriate decisions by people skilled and interested in these issues. 
This study contributes at a theoretical level to a structuring of information on the exhaustion syndrome at work among teachers, as well as to a highlight of how teachers experience it in a pandemic context. At a practical level, the study contributes to the validation of a working tool, by translating items into Romanian and certifying the reliability of items, as well as to outlining a reality that would be the basis for decisions by directors regarding methods to prevent exhaustion. or proactive strategies to reduce burnout.

\section{LIMITS OF THE RESEARCH AND FUTURE RESEARCH}

The limitations of this study may be related to the small size of the sample, which determines that the results not be generalized, its running in the online environment which led to a low participation rate of respondents, failure to take into account other influencing factors.

However, this study is a solid basis for the development of future studies, targeting other variables such as: job satisfaction, employee empowerment, organizational support, work environment, time management. Future research may also take into account a qualitative part of the research design, in order to identify more developed answers from the respondents, respectively to run a comparative analysis on different professional occupations. Also, future research may continue to explore the impact of the pandemic context on educational requirements and implicitly on the exhaustion syndrome experienced by teachers. 


\section{REFERENCES}

1. Ajayi, L., 2016. A review of: The Test: Why our schools are obsessed with standardized testing - but you don't have to be. Wisdom in Education, 6(1), pp. 1-3.

2. APA Dictionary of Psychology, 2020. American Psychological Association. [Online] Available at: https://dictionary.apa.org/

[Accessed 2 October 2021].

3. Ávalos, B., 2011. Teacher professional development in teaching and teacher education over ten years.. Teaching and Teacher Education: An International Journal of Research and Studies, 27(1), pp. 10-20.

4. Beheshtifar, M. and Omidvar, A., 2013. Causes to Create Job Burnout in Organizations.. International Journal of Academic Research in Business and Social Sciences., Volume 3, pp. 2222-6990.

5. Bohâlțeanu, S., 2021. Educația în era digitală -provocări educaționale în context pandemic.. București, Centrul de Resurse Educaționale, pp. 2872-2875.

6. Cordes, C. L. and Dougherty, T. W., 1993. A Review and an Integration of Research on Job Burnout.. The Academy of Management Review., 18(4), pp. 621-656.

7. Deloitte, 2019. Workplace Burnout Survey. Burnout without borders. [Online] Available at: https://www2.deloitte.com/us/en/pages/about-deloitte/articles/burnout-survey.html [Accessed 02 October 2021].

8. Dierking, R. C. and Fox, R. F., 2013. Changing the Way I Teach": Building Teacher Knowledge, Confidence, and Autonomy. Journal of Teacher Education, 62(2), pp. 129-144.

9. Diliberti, M. K., Heather, L. S. and David, G., 2021. Stress Topped the Reasons Why Public School Teachers Quit, Even Before COVID-19. Calif.: RAND Corporation, p.38.

10. Drummond, D., 2016. Part I: Burnout Basics - Symptoms, Effects, Prevalence and the Five Main Causes. Missouri medicine, 113(4), p. 252-255.

11. European Training Foundation, 2020. Teachers play an important role in boosting learners' engagement in education affected by the COVID-19 pandemic. [Online] Available at: https://www.etf.europa.eu/en/news-and-events/news/teachers-play-important-roleboosting-learners-engagement-education-affected

[Accessed 2 October 2021].

12. Fernet, C., Guay, F., Senecal, C. B. and Austin, S. L., 2012. Predicting intraindividual changes in teacher burnout: The role of perceived school environment and motivational factors.. Teaching and Teacher Education. An International Journal of Research and Studies, 28(4), pp. 514-525.

13. Freudenberger, H., 1975. The staff burn-out syndrome in alternative institutions. Psychotherapy: Theory, Research \& Practice, 12(1), pp. 73-82.

14. Gaitan, P. E., 2009. Teacher Burnout Factors as Predictors of Adherence to Behavioral Intervention. A dissertation submitted to the faculty of the graduate school of the University of Minnesota, p. 109.

15. Heinemann, L. and Heinemann, T., 2017. Burnout Research: Emergence and Scientific Investigation of a Contested Diagnosis. SAGE Open, pp. 1-12.

16. Jacobson, D. A., 2016. Causes and Effects of Teacher Burnout. Walden University. ProQuest Dissertations Publishing, p. 161.

17. Jennett, H. K., Harris, S. L. and Gary, B. M., 2003. Commitment to Philosophy, Teacher Efficacy, and Burnout Among Teachers of Children with Autism.. Journal of Autism and Developmental Disorders, 36(3), pp. 583-593.

18. Johnson, S. et al., 2005. The experience of work-related stress across occupations.. Journal of Managerial Psychology, 20(2), pp. 178-187.

19. Kaschka, W. P., Korczak, D. and Broich, K., 2011. Burnout: a fashionable diagnosis. Deutsches Arzteblatt international, 108(46), pp. 781-787. 
20. Lanier, J. T., 1997. Redefining the Role of the Teacher: It's a Multifaceted Profession. A closer look at what being an educator really means.. [Online]

Available at: https://www.edutopia.org/redefining-role-teacher

[Accessed 2 October 2021].

21. Leung, D. Y. P. and Lee, W. W. S., 2006. Predicting intention to quit among Chinese teachers: differential predictability of the components of burnout. Anxiety, Stress \& Coping, 19(2), pp. 129-141.

22. Lowenstein, L., 1991. Teacher stress leading to burnout: Its prevention and cure.. Education Today., Volume 41, pp. 12-16.

23. Maslach, C. and Jackson, S. E., 1981. The measurement of experienced burnout. Journal of occupational behaviour, Volume 2, pp. 99-113.

24. Maslach, C. and Leiter, M. P., 2016. Understanding the burnout experience: recent research and its implications for psychiatry. World psychiatry: official journal of the World Psychiatric Association (WPA), 15(2), p. 103-111.

25. McAllister, P., 2018. A Teacher's Perspective on What's Wrong with Our Schools. Cato Journal, 38(1).

26. Mogonea, F. R. and Mogonea, F., 2021. Impact of the COVID-19 pandemic on the burnout. Annals of the university of Craiova, Psychology - Pedagogy, 43(1), pp. 37-47.

27. Nikcevic, A. V. and Spada, M. M., 2020. The COVID-19 Anxiety Syndrome Scale: Development and psychometric properties.. Psychiatry Research, p. 36.

28. Norhisham, N., Husain, N. A., Abas, N. M. and Haza, N. I. F., 2021. Factors of Job Burnout among Female Teachers: A Study on Female Secondary School Teachers in a District of Johor. International ournal of Academic Research in Business and Social Sciences, 11(8), p. 456-467.

29. Pressley, T., 2021. Factors Contributing to Teacher Burnout During COVID-19. 50(5), pp. 325-327.

30. Psychology Today, n.d. Burnout. [Online]

Available at: https://www.psychologytoday.com/intl/basics/burnout

[Accessed 02 October 2021].

31. Pyhältö, et al., 2021. Teacher burnout profiles and proactive strategies. European Journal of Psychology of Education, Volume 36, pp. 219-242.

32. Reeves, D. B., 2012. Confront Teacher Burnout with More Safety, Time, and R-E-S-P-E-C-T. Avoiding Teacher Burnout, 15 March, 7(12).

33. Salvagioni, D. et al., 2017. Physical, psychological and occupational consequences of job burnout: A systematic review of prospective studies.. PloS one, 12(10), p. 29.

34. Sánchez-Pujalte, L., Mateu, D., Etchezahar, E. and Gómez, Y. T., 2021. Teachers' Burnout during COVID-19 Pandemic in Spain: Trait Emotional Intelligence and Socioemotional Competencies.. Sustainability, 13(13), p. 7259.

35. Schaufeli, W. B., Marek, T. and Maslach, C., 1993. Professional burnout: Recent developments in theory and research.. In: W. B. Schaufeli, C. Maslach \& T. Marek, eds. s.l.:Routledge, pp. 1-47.

36. Schaufeli, W. B. and van Dierendonck, D., 1993. The Construct Validity of Two Burnout Measures.. Journal of Organizational Behavior., 14(7), pp. 631-647.

37. School of Education, 2021. Addressing Teacher Burnout: Causes, Symptoms, and Strategies.

[Online]

Available at: https://soeonline.american.edu/blog/teacher-burnout

[Accessed 2 October 2021].

38. Shen, B. et al., 2015. The relationship between teacher burnout and student motivation.. British Journal of Educational Psychology, 85(4), pp. 519-532.

39. Skaalvik, E. M. and Skaalvik, S., 2010. Teacher self-efficacy and teacher burnout: A study of relations. Teaching and Teacher Education, 26(4), pp. 1059-1069.

40. Smetackova, I. et al., 2019. Teachers Between Job Satisfaction and Burnout Syndrome: What Makes Difference in Czech Elementary Schools. Frontiers in Psychology, Volume 10, p. 2287. 
41. Sokal, L. J., Eblie, T., Lesley, G. B. and Jeff, C., 2020. Supporting Teachers in Times of Change: The Job Demands- Resources Model and Teacher Burnout During the COVID-19 Pandemic. International Journal of Contemporary Education, 3(2), pp. 67-74.

42. The graide net work, 2019. Teacher Burnout Solutions \& Prevention - How to Retain Talented Educators. [Online]

Available at: https://www.thegraidenetwork.com/blog-all/teacher-burnout-solutions-prevention [Accessed 2 October 2021].

43. Warr, P., 2007. Work, Happiness, and Unhappiness. Mahwah: NJ: Lawrence Erlbaum Associates.

44. Weißenfels, M., Klopp, E. and Perels, F., 2021. Changes in Teacher Burnout and Self-Efficacy During the COVID-19 Pandemic: Interrelations and Variables Related to Change. [Online] Available at: https://psyarxiv.com/54wub/ [Accessed 2 October 2021].

45. World Health Organization, 2019. Burn-out an "occupational phenomenon": International Classification of Diseases. [Online]

Available at: https://www.who.int/news/item/28-05-2019-burn-out-an-occupationalphenomenon-international-classification-of-diseases

[Accessed 2 October 2021]. 